\title{
Analisis Kegagalan Poros Shipping Pump Pada Anjungan Produksi Minyak dan Gas Bumi Lepas Pantai
}

\author{
W. D. Putra* dan P. T. Iswanto \\ Departemen Teknik Mesin dan Industri, Fakultas Teknik, Universitas Gadjah Mada. \\ Jl. Grafika No.2, Kompleks UGM, Yogyakarta 55281, Indonesia, \\ Telp. (0274) 521673 \\ *e-mail:wdputra82@yahoo.com
}

\begin{abstract}
Abstrak
Shipping Pump adalah peralatan kritikal dari proses produksi minyak mentah di anjungan produksi lepas pantai karena berfungsi mengalirkan hasil produksi ke proses selanjutnya di darat. Pada tanggal 19 Mei 2018 ditemukan poros pompa Shipping Pump P-1B yang berbahan baja tahan karat AISI 316 patah pada bagain atas, di dalam susunan kopling. Penelitian ini bertujuan untuk mengetahui model dan penyebab kegagalan poros yang terjadi. Metodelogi penelitian yang digunakan adalah studi kasus dengan pengamatan pola patahan secara mikroskopis menggunakan Scanning Electron Microscope (SEM) dan verifikasi bahan poros. Analisis tegangan yang terjadi di poros juga dilakukan untuk membandingkan besar tegangan kerja dengan tegangan batas fatik poros. Dari hasil pengamatan pada penampang patahan menunjukkan model kegagalan yang terjadi adalah kegagalan fatik berdasarkan adanya awal retak di ujung alur pasak, adanya daerah pertumbuhan retak lambat dan daerah patah seketika. Hasil pengujian metalografi, komposisi kimia, pengujian tarik dan kekerasan Brinnel menunjukkan bahwa bahan poros sesuai dengan standar bahan AISI 316. Poros dapat mengalami kegagalan fatik karena tegangan kerja lebih besar dari tegangan batas fatik komponen dan faktor terbesar yang mengurangi nilai tegangan batas fatik adalah faktor konsenstrasi tegangan dimana radius alur pasak sangat kecil.
\end{abstract}

Kata kunci : shipping pump, poros, AISI 316, fatik.

\begin{abstract}
Shipping Pump is a critical equipment of the crude oil production process on an offshore production platform because its functions to flow crude oil to the next process onshore. On May 19, 2018, the Shipping Pump P-1B shaft made from stainless steel AISI 316 was broken in the upper section, inside the coupling assembly. This study aims to determine the model and causes of shaft failure that occur. In this research microscopic fracture patterns were observed using the Scanning Electron Microscope (SEM). Verification of shaft material is done by comparing the results of metallographic testing, chemical composition testing, tensile testing and Brinnel hardness testing with AISI 316 material standards. Stress analysis is carried out to compare the working stress with the shaft fatigue limit stress. The results of observations on the fracture cross-section shows the failure model that occurs is a fatigue failure based on the initial crack at the end of the keyway, the presence of the slow crack growth area and the instantaneous fracture area. Metallographic, chemical composition, tensile and Brinnel hardness tests show that the shaft material complies with AISI 316 material standards. The shaft may
\end{abstract}


experience fatigue failure because the working stress is greater than the component fatigue stress and the biggest factor that reduces the value of the fatigue limit stress is the concentration factor stress where the radius of the keyway is very small.

Keywords : shipping pump, shaft, AISI 316, fatigue.

\section{PENDAHULUAN}

Shipping Pump adalah peralatan kritikal dari proses produksi minyak mentah di anjungan produksi lepas pantai karena berfungsi mengalirkan hasil produksi ke proses selanjutnya di darat. Hal ini yang mendasari dalam desain awal selalu disiapkan lebih dari satu Shipping Pump agar saat terjadi kerusakan pada salah satu pompa masih ada penggantinya agar proses produksi masih tetap berjalan. Kegagalan dari Shipping Pump akan menurunkan produksi dan bahkan dapat menyebabkan berhentinya proses produksi minyak bumi dikarenakan tidak adanya peralatan yang dapat mengirimkan hasil produksi. Pada tanggal 19 Mei 2018 operator produksi menemukan Shipping Pump P-1B mengalami penurunan unjuk kerja yang signifikan diindikasikan oleh berkurangnya debit alirnya setelah bekerja selama tiga hari. Kemudian setelah dilakukan pemeriksaan, ditemukan poros pompa yang berbahan baja tahan karat AISI 316, pada bagian atasnya patah seperti yang ditunjukkan pada sketsa susunan kopling pada Gambar 1. Secara praktikal di lapangan, kegagalan dikategorikan sebagai berikut: kegagalan karena beban berlebih, kelelahan, kelelahan yang dipengaruhi korosi, korosi, dan keausan. Dan penyebab paling umum dari kegagalan poros adalah kelelahan. Kegagalan karena kelelahan dimulai pada titik yang paling rentan, yaitu di daerah yang mendapat tegangan secara dinamis biasanya bertipe stress raiser, yang mungkin bersifat metalurgi atau mekanis, dan kadang-kadang keduanya.

Berdasarkan latar belakang di atas, didapat perumusan masalah yang akan di analisis pada penelitian yakni model kegagalan yang terjadi, proses terjadinya dan mengapa terjadi kegagalan pada poros Shipping Pump P-1B serta rekomendasi untuk mencegah kegagalan serupa. Tujuan dari pelaksanaan penelitian ini adalah untuk mengetahui model kegagalan, proses terjadinya kegagalan, penyebab kegagalan yang terjadi pada poros Shipping Pump P-1B dan untuk mendapatkan rekomendasi dalam rangka mencegah kegagalan serupa.

Haryadi dkk menganalisis penyebab terjadinya kegagalan pada poros pompa sirkulasi air yang berbahan baja tahan karat AISI 316. Pengujian komposisi kimia, pengujian kekerasan Vickers, pengujian metalografi, dan scanning electron microscopy (SEM) dilakukan. Dapat disimpulkan bahwa kegagalan poros pompa terjadi karena porositas dan indikasi dari getaran yang berlebih akibat kerusakan pada bearing. Retakan utama dimulai di tengah poros yang terindikasi ada porositas.

Supriyono dan Adjiantoro meganalisis kegagalan poros berbahan AISI 316 pada pompa tipe sentrifugal penyalur air laut unit penukar panas. Untuk mengetahui faktor penyebab kegagalan, maka dilakukan pengamatan visual, pengujian fraktografi, metalografi, uji kekerasan, dan analisa komposisi kimia pada poros yang patah. Dari hasil pengujian diperoleh bahwa kadar karbon rata-rata lebih rendah dari standar AISI 316, sedangkan kekerasan rata-ratanya lebih rendah dari kekerasan standarnya. Kegagalan yang terjadi, pada dasarnya disebabkan oleh patah lelah akibat beban kerja berlebih berupa pembebabanan dinamis. 


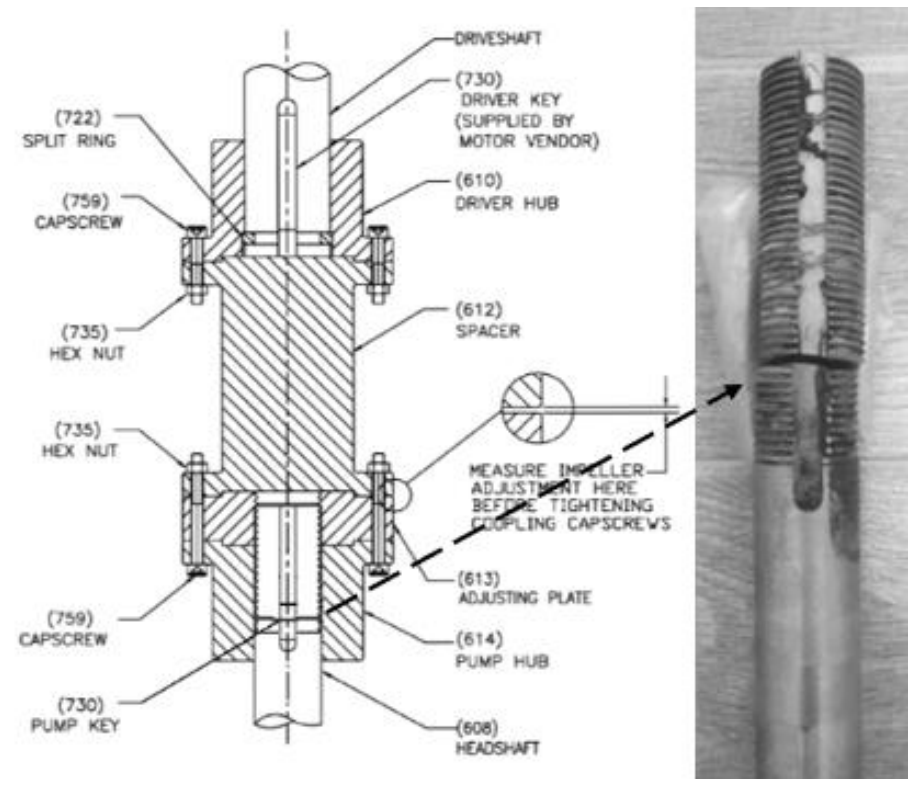

Gambar 1. Sketsa dan foto bagian poros yang patah di dalam susunan kopling

\section{METODE PENELITIAN}

Dalam penelitian ini dilakukan pengamatan pola patahan secara mikroskopis, yaitu dengan menggunakan mikroskop elektron (SEM). Verifikasi bahan poros dilakukan dengan membandingkan hasil pengujian metalografi, pengujian komposisi kimia, pengujian tarik dan pengujian kekerasan Brinnel dengan standar bahan AISI 316. Analisis tegangan juga dilakukan untuk mengetahui tegangan kerja pada poros dan membandingkannya dengan tegangan batas fatik.

\subsection{Peralatan}

Alat-alat yang dipergunakan dalam pembuatan spesimen uji dan pelaksanaan pengngujian adalah sebagai berikut:

1. Mesin pemotong bahan

2. Penggaris dan jangka sorong

3. Kamera digital

4. Perangkat pengujian metalografi berupa mounting, grinding/polishing, dan etching.

5. Mikroskop optik

6. Alat uji komposisi kimia spectrometer

7. Mikroskop elektron (SEM)

8. Mesin uji tarik

9. Mesin uji kekerasan Brinnel

\subsection{Bahan}

Bahan yang digunakan dalam penelitian ini adalah poros dari Shipping Pump P-1B yang mengalami kegagalan. Material dari poros yakni baja tahan karat AISI 316 berdiameter 25,4 mm dan panjang $1722 \mathrm{~mm}$. Foto penampang poros bagian atas dan bawah yang mengalami patahan dapat dilihat pada Gambar 2. 


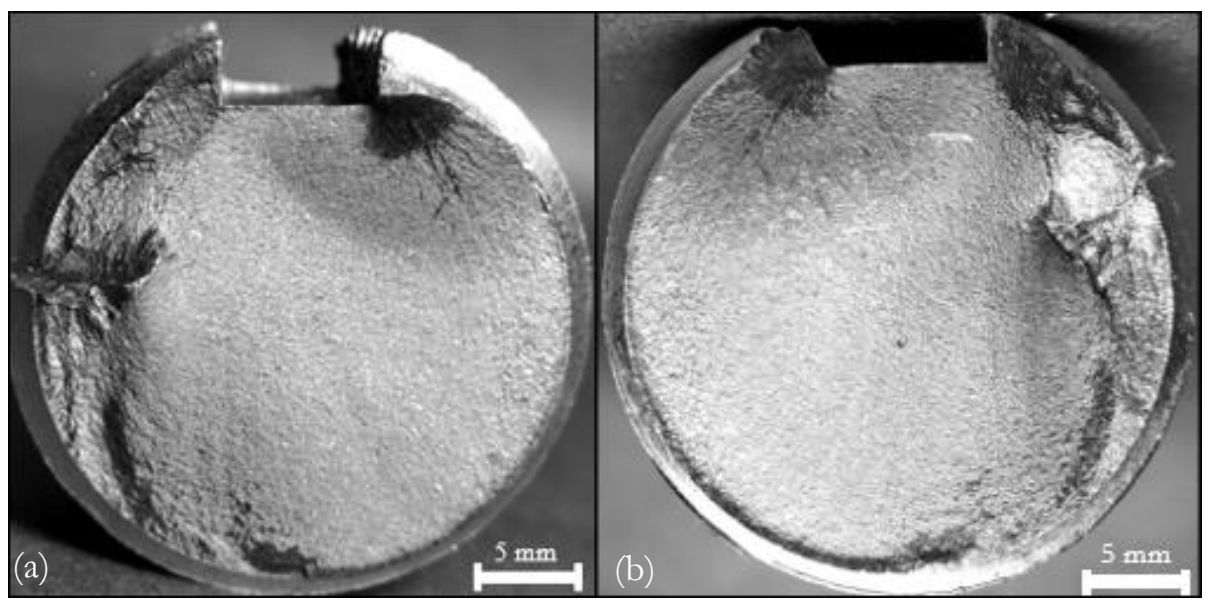

Gambar 2. Foto penampang poros yang mengalami patahan (a) bagian atas dan (b)bagian bawah

\subsection{Prosedur Penelitian}

Prosedur penelitian yang dilakukan pada analisis kegagalan ini adalah sebagai berikut:

1. Pengamatan Lapangan

Pengamatan lapangan bertujuan untuk mendapatkan data awal tentang kondisi operasional, sejarah pemakaian, spesifikasi pompa dan inspeksi visual.

2. Pengujian SEM

Pengujian SEM bertujuan untuk dilakukan pengamatan fraktografi, yaitu mengetahui profil permukaan patahan secara mikro. Sampel yang diambil untuk pengujian SEM ini adalah penampang poros Shipping Pump yang patah dengan ukuran $1 \mathrm{~cm}^{3}$ disesuaikan dengan kapasitas chamber alat uji SEM.

3. Verifikasi bahan poros

\section{A. Pengujian Metalografi}

Pengujian metalografi dilakukan untuk mengetahui struktur mikro yang terdapat pada poros Shipping Pump dan kemudian dibandingkan dengan struktur mikro baja than karat AISI 316 sesuai ASM Handbook Vol. 9 (Metallography and Microstructur). Persiapan spesimen meliputi pemotongan spesimen yang diambil dari sisa patahan poros Shipping Pump berdiameter 25,4 mm, grinding dan polishing agar permukaan spesimen rata, dan proses etsa dengan $\mathrm{HCl}, \mathrm{HNO}_{3}$, dan air dalam komposisi setara.

B. Pengujian Komposisi Kimia

Pengujian sifat fisis berupa uji komposisi kimia dilakukan untuk mengetahui komposisi aktual dari poros yang patah menggunakan alat Spectrometer untuk kemudian dibandingkan dengan standar komposisi kimia baja tahan karat AISI 316. Spesimen yang digunakan diambil dari sisa patahan poros Shipping Pump berdiameter 25,4 mm.

\section{Pengujian Tarik}

Pengujian tarik dilakukan untuk mengetahui nilai tegangan tarik maksimum dari poros Shipping Pump untuk kemudian dibandingkan dengan nilai standar tegangan tarik maksimum baja tahan karat AISI 316. Nilai tegangan tarik maksimum ini juga akan digunakan sebagai data untuk pengujian fatik rotary bending jika diperlukan untuk mengetahui batas fatik. Persiapan spesimen meliputi pemotongan spesimen yang 
diambil dari sisa patahan poros Shipping Pump berdiameter 25,4 $\mathrm{mm}$ dan pembubutan spesimen agar sesuai dengan dimensi uji tarik mengacu pada ASTM E8M.

D. Pengujian Kekerasan

Pengujian kekerasan dilakukan untuk mengetahui ketahanan bahan terhadap identasi permukaaan dari identor atau goresan yang diterima. Metode uji kekerasan yang dipergunakan dalam penelitian ini adalah metode Brinnel dimana indentor bola baja berdiameter 2,5 mm ditekan dengan beban tetap sebesar $100 \mathrm{~kg}$ ke permukaan suatu bahan.

4. Analisis Tegangan

Analisis tegangan dilakukan untuk membandingkan tegangan kerja poros berupa tegangan geser maksimum dengan batas fatik komponen. Kegagalan dapat terjadi jika tegangan kerja poros lebih besar dari batas fatik komponen. Tegangan kerja yang terjadi dapat diketahui dengan menggunakan persamaan tegangan geser utama sebagai berikut:

dimana

$$
\tau_{\max }=\sqrt{\left(\frac{\sigma_{x}-\sigma_{y}}{2}\right)^{2}+\left(\tau_{x y}\right)^{2}}
$$

$\tau_{\max } \quad$ : tegangan geser utama (principal shear stress) $(\mathrm{MPa})$

$\sigma_{\mathrm{x}} \quad$ : tegangan tarik pada arah sumbu-x $(\mathrm{MPa})$

$\sigma_{\mathrm{y}} \quad$ : tegangan tarik pada arah sumbu-y $(\mathrm{MPa})$

$\tau_{\mathrm{xy}} \quad:$ tegangan geser pada bidang tegak lurus sumbu-x dengan arah sumbuy $(\mathrm{MPa})$

Ketika data laboratorium mengenai batas fatik setiap bahan tidak tersedia, ada perkiraan hubungan antara batas fatik dan kekuatan tarik maksimum dari bahan. Perkiraan batas fatik dari baja adalah sebagai berikut:

$$
S_{e}^{\prime}=0,5 S_{u t}
$$

dimana

$\mathrm{S}_{\mathrm{e}} \quad$ : tegangan batas fatik specimen uji fatik yang mengalami tegangan lentur terbalik $(\mathrm{MPa})$

$\mathrm{S}_{\mathrm{ut}} \quad$ : tegangan tarik maksimum $(\mathrm{MPa})$

Batas fatik suatu komponen berbeda dari batas fatik spesimen uji fatik karena sejumlah faktor. Perbedaan timbul karena ada spesifikasi standar dan kondisi kerja tertentu untuk spesimen uji fatik, sedangkan komponen yang sebenarnya berbeda spesifikasi dan juga bekerja di bawah kondisi yang berbeda. Faktor modifikasi yang berbeda digunakan dalam praktik untuk memperhitungkan perbedaan ini. Tujuan dari faktor modifikasi ini adalah menurunkan atau mengurangi batas fatik spesimen agar sesuai dengan kondisi sebenarnya dari komponen. Empat faktor yang mempengaruhi nilai tegangan batas fatik komponen yang mengalami tegangan lentur dijabarkan pada persamaan berikut[6]:

dimana

$$
S_{e}=K_{a} K_{b} K_{c} K_{d} K_{e} S_{e}^{\prime}
$$

$\mathrm{S}_{\mathrm{e}} \quad$ : tegangan batas fatik komponen yang mengalami tegangan lentur terbalik $(\mathrm{MPa})$

$\mathrm{S}_{\mathrm{e}} \quad$ : tegangan batas fatik specimen uji fatik yang mengalami tegangan lentur terbalik $(\mathrm{MPa})$

$\mathrm{K}_{\mathrm{a}} \quad$ : faktor penyelesaian permukaan

$\mathrm{K}_{\mathrm{b}} \quad$ : faktor ukuran 
$\mathrm{K}_{\mathrm{c}} \quad$ : faktor keandalan

$\mathrm{K}_{\mathrm{d}} \quad$ : faktor modifikasi untuk memperhitungkan konsentrasi tegangan

Batas fatik dari suatu komponen yang mengalami tegangan geser puntir yang berfluktuasi $\left(\mathrm{S}_{\mathrm{se}}\right)$ dapat diperoleh dari batas fatik komponen yang mengalami tegangan lentur terbalik $\left(\mathrm{S}_{\mathrm{e}}\right)$ dengan menggunakan teori kegagalan. Menurut teori tegangan geser maksimum hubungan antara Sse dan Se dijabarkan pada persamaan berikut[6]:

dimana

$$
S_{s e}=0,5 S_{e}
$$

$\mathrm{S}_{\mathrm{se}} \quad$ : tegangan geser puntir yang berfluktuasi $(\mathrm{MPa})$

$\mathrm{S}_{\mathrm{e}} \quad$ : tegangan batas fatik komponen yang mengalami tegangan lentur terbalik $(\mathrm{MPa})$

5. Pembahasan dan analisis data

Pembahasan dan analisis data digunakan untuk mengolah data yang diperoleh dari observasi dan pengujian yang dilakukan sehingga dapat menjelaskan model, proses terjadinya dan penyebab kegagalan. Dari prosedur ini selanjutnya bisa dihasilkan kesimpulan dan saran penelitian.

\section{HASIL DAN PEMBAHASAN}

\subsection{Pengujian SEM}

Pada Gambar 3. (a) dan (b) menunjukkan adanya jejak garis yang berpusat ke ujung alur pasak (keyway) sisi kanan. Ujung alur pasak sisi kanan ini diidentifikasi sebagai initial crack karena pada alur pasak terjadi konsentrasi tegangan dan jika dilihat dari arah putaran poros, pada alur pasak sisi kanan adalah daerah yang terdesak oleh pasak yang mentransmiskan putaran kopling dari motor ke poros.

Dari Gambar 3 (a) juga dapat dilihat ada dua daerah kegagalan fatik, yaitu daerah yang menunjukkan pertumbuhan retak yang lambat dengan penampakan serat yang halus (daerah sisi kanan penampang) dan daerah patah mendadak dengan penampakan butiran kasar (daerah sisi kiri penampang). Adanya awal retak, pertumbuhan retak yang lambat dan daerah patah mendadak menunjukan kegagalan yang terjadi adalah kegagalan fatik. Tidak adanya penampakan beach mark dan striasi yang jelas sebagai salah satu ciri kegagalan fatik tidak mengesampingkan bahwa kegagalan yang terjadi karena fatik. Beach mark atau stiriasi yang berada pada skala finerscale biasanya terbentuk ketika beban berubah selama operasi atau ketika terjadi pembebanan mendadak ${ }^{[6]}$, sedangkan Shipping Pump beroperasi dalam dalam putaran relatif konstan dan motornya dilengkapi dengan VSD (Variable Speed Drive) yang dapat mengatur putaran motor secara perlahan jika ada penambahan atau pengurangan beban.

\subsection{Verifikasi Bahan}

\subsubsection{Pengujian Metalografi}

Pengujian ini menggunakan cairan etsa $\mathrm{HCl}, \mathrm{HNO}_{3}$, dan air dalam komposisi setara. Gambar 4 menunjukan hasil perbandingan metalografi antara bahan poros Shipping Pump dengan pembesaran 100x dengan metalografi baja tahan karat AISI 316 sesuai ASM Handbook dimana tidak ada perbedaan mencolok antara keduanya. Keduanya menunjukkan struktur austenitik yang ditunjukkan oleh adanya karakteristik twinning. Twinning adalah tipikal dari struktur kristal FCC berupa dua garis sejajar pada foto struktur mikro. 


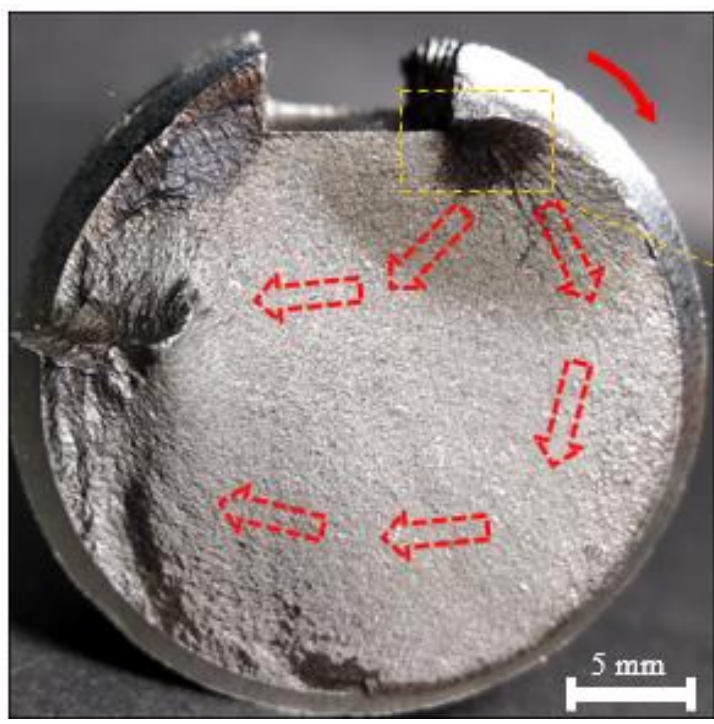

a

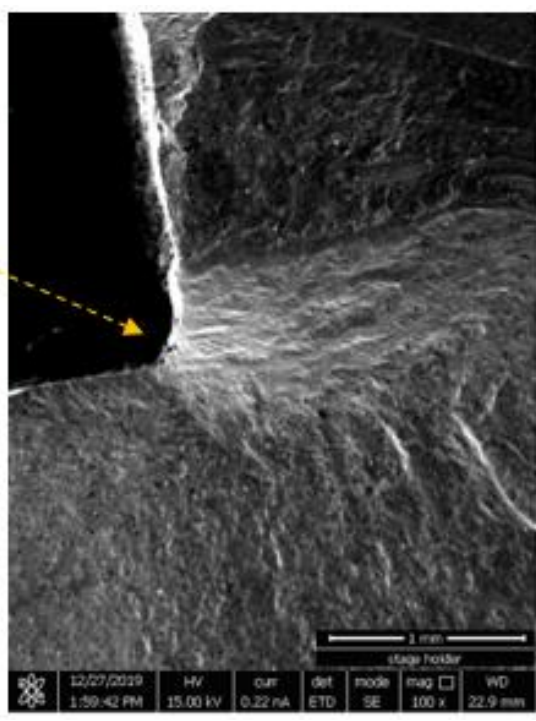

$\mathrm{b}$

Gambar 3. (a) Penampang patahan poros bagian atas dan arah rambatan retak (b) Hasil pengujian SEM pembesaran 100x pada initial crack.

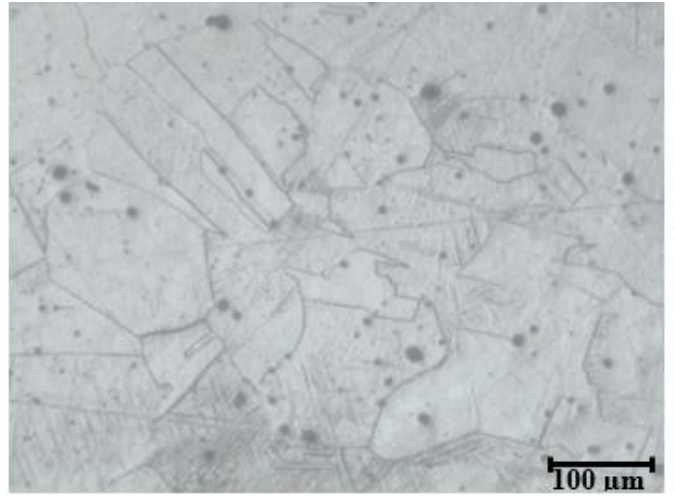

a

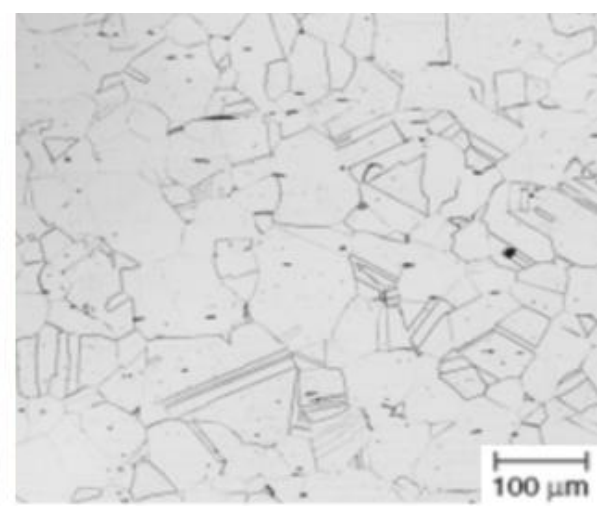

$\mathrm{b}$

Gambar 4. Hasil metalografi (a) bahan poros Shipping Pump dengan perbesaran 100x (b) baja tahan karat AISI 316 sesuai ASM Handbook Volume 9 perbesaran 500x

\subsubsection{Pengujian Komposisi Kimia}

Hasil pengujian komposisi kimia bahan poros Shipping Pump dengan spektrometer analyzer ditunjukkan pada Tabel 1. Jika dibandingkan dengan komposisi kimia baja tahan karat AISI 316 standar, hampir semua persentase komposisi kimia hasil pengujian memiliki kesamaan kecuali unsur Mo yang sedikit di bawah standar minimal. Kekurangan unsur Mo ini dapat berpengaruh pada berkurangnya ketahanan baja tahan karat terhadap korosi sumuran pada larutan klorida.

Unsur lain yang sedikit berbeda dari standart adalah unsur C yang memiliki komposisi 0,019\%, meskipun masih dalam standar tetapi bisa menimbulkan persepsi bahwa bahan poros ini adalah baja tahan karat AISI 316L. Baja tahan karat AISI 316L memiliki komposisi kimia yang sama dengan AISI 316 kecuali komposisi unsur C lebih rendah, yaitu 
W. D. Putra dan P. T. Iswanto / Journal of Mechanical Design and Testing 2(2), (2020), 137-146

maksimal 0,03 \% (ASTM, 2004). Kepastian jenis bahan poros Shipping Pump bisa dikonfirmasi dengan hasil pengujian selanjutnya, yaitu dari hasil uji tarik dan kekerasan.

Tabel 1. Hasil uji komposisi kimia

\begin{tabular}{llllllllll}
\hline \multicolumn{2}{l}{ Komposisi Kimia } & $\mathbf{C}$ & $\mathbf{M n}$ & $\mathbf{S i}$ & $\mathbf{P}$ & $\mathbf{S}$ & $\mathbf{C r}$ & $\mathbf{M o}$ & $\mathbf{N i}$ \\
\hline $\begin{array}{l}\text { Standar } \\
\text { AISI }\end{array} \mathbf{M i n}$ & - & - & - & - & - & 16,0 & 2,0 & 10,0 \\
$\mathbf{( \% )}$ & $\mathbf{M a x}$ & 0,08 & 2,0 & 1,0 & 0,045 & 0,03 & 18,0 & 3,0 & 14,0 \\
\hline Sample Uji (\%) & 0,019 & 1,701 & 0,418 & 0,035 & 0,018 & 16,357 & 1,806 & 10,074 \\
\hline
\end{tabular}

\subsubsection{Pengujian Tarik}

Hasil pengujian tarik dibandingkan dengan standar bahan baja tahan karat AISI 316 ditunjukkan pada Tabel 2 di bawah.

Tabel 2. Hasil pengujian tarik dan kekerasan

\begin{tabular}{lll}
\hline & UTS (MPa) & BHN $\left.\mathbf{( k g} / \mathbf{m m}^{2}\right)$ \\
\hline Hasil Uji & 611,31 & 199,16 \\
\hline Standar AISI 316 & Min 515 & Maks 217 \\
\hline
\end{tabular}

Dari Tabel 2 di atas dapat dilihat tegangan tarik maksimum (UTS) adalah sebesar 611,31 MPa. Hasil pengujian ini memenuhi standar minimum UTS dari bahan AISI 316, yaitu minimum sebesar $515 \mathrm{MPa}$.

\subsubsection{Pengujian Kekerasan}

Hasil pengujian kekerasan yang ditunjukkan pada table 2 dapat dilihat angka kekerasan Brinnel (BHN) dari poros Shipping Pump, yaitu 199,16 kg/mm² masih memenuhi standar bahan AISI 316, yakni maksimum sebesar $217 \mathrm{~kg} / \mathrm{mm}^{2}$.

\subsection{Analisis Tegangan}

\subsubsection{Tegangan Kerja}

Jenis Shipping Pump yang dianalisis ini adalah pompa sentrifugal dengan poros vertikal dimana terdapat dua tegangan yang bekerja pada porosnya, yaitu (1) tegangan geser puntir $(\tau)$ karena putaran motor $(\mathrm{T})$ dan $(2)$ tegangan aksial $(\sigma)$ karena berat komponen yang berputar dan axial thrust (Presultan). Gambar 5 memperlihatkan ilustrasi tegangan yang bekerja pada poros Shipping Pump Vertikal.

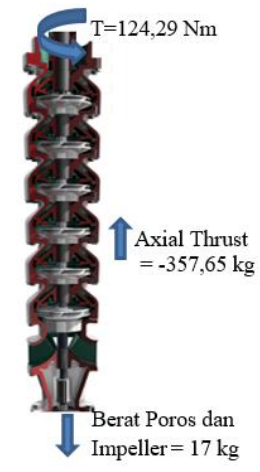

Gambar 5. Ilustrasi tegangan kerja pada poros Shipping Pump vertikal 
Tegangan geser puntir adalah tegangan pada poros yang disebabkan oleh torsi (puntiran) motor. Dengan torsi maksimum motor adalah 91,67 lb-ft $(124,29 \mathrm{Nm})$ sesuai spesifikasi pompa dan diameter efektif dari poros adalah $23 \mathrm{~mm}(0,023 \mathrm{~m})$, maka tegangan geser puntir adalah 52,05 Mpa.

Tegangan tarik pada poros terjadi karena berat peralatan yang berputar dan dorongan aksial yang disebabkan karena perbedaan tekanan pada sisi isap dan tekan pada impeller pompa. Berat peralatan yang berputar, yaitu poros dan impleller sebesar $17 \mathrm{~kg}$. Dorongan aksial dapat diketahui dari konstanta dorongan yang ada pada kurva kinerja pompa, yaitu sebesar 3,1 lbs/ft per head, sehingga head pompa adalah sebesar 254,35 ft maka dorongan aksial adalah $-788,45 \mathrm{lbs}$ atau $-357,65 \mathrm{~kg}$ (bernilai minus karena berlawanan arah dengan berat komponen berputar). Dari berat poros dan impeller serta dorongan aksial di atas, dapat diketahui nilai tegangan tarik adalah -8,04 MPa.

Jika nilai tegangan geser puntir dan tegangan tarik sudah diketahui, maka tegangan kerja pada poros berupa tegangan geser maksimum bisa diketahui menggunakan persamaan tegangan geser utama (1)

$$
\begin{aligned}
\tau_{\text {max }} & =\sqrt{\left(\frac{\sigma_{x}-\sigma_{y}}{2}\right)^{2}+\left(\tau_{x y}\right)^{2}} \\
\tau_{\text {max }} & =\sqrt{\left(\frac{0-(-8,04}{2}\right)^{2}+(52,05)^{2}}=52,2 \mathrm{MPa}
\end{aligned}
$$

\subsubsection{Batas Fatik}

Dengan tegangan tarik maksimum $\left(\mathrm{S}_{\mathrm{ut}}\right)$ dari hasil uji tarik adalah 618,31 $\mathrm{MPa}$, maka dari persamaan (2) batas fatik adalah

$S_{e}^{\prime}=0,5 S_{u t}$

$S^{\prime}{ }_{e}=0,5(611,31 \mathrm{MPa})=305,655 \mathrm{MPa}$

Jika diketahui $\mathrm{K}_{\mathrm{a}}=0,76, \mathrm{~K}_{\mathrm{b}}=0,85, \mathrm{~K}_{\mathrm{c}}=0,834$, dan $\mathrm{K}_{\mathrm{d}}=0,34$, maka batas fatik komponen $\left(\mathrm{S}_{\mathrm{e}}\right.$ ) dapat dihitung dengan persamaan (3)

$S_{e}=K_{a} K_{b} K_{c} K_{d} K_{e} S_{e}^{\prime}$

$S_{e}=(0,76)(0,85)(0,834)(0,34)(305,655 \mathrm{MPa})=55,9 \mathrm{MPa}$

Batas fatik dari suatu komponen yang mengalami tegangan geser puntir yang berfluktuasi $\left(\mathrm{S}_{\mathrm{se}}\right)$ dapat diperoleh dari batas fatik komponen yang mengalami tegangan lentur terbalik $\left(\mathrm{S}_{\mathrm{e}}\right)$ dengan menggunakan persamaan (4) berikut:

$S_{\text {se }}=0,5 S_{e}$

$S_{s e}=0,5(55,9 \mathrm{Mpa})=27,95 \mathrm{MPa}$

Dari hasil pengujian dan pembahasan di atas, melalui verifikasi bahan dapat diketahui bahwa komposisi bahan, kekuatan tarik, nilai kekerasan dan struktur mikro poros sesuai dengan spesifikasi baja tahan karat AISI 316. Dari hasil uji SEM didapatkan adanya ciri kegagalan fatik yaitu daerah awal retak, pertumbuhan retak lambat dan daerah patah mendadak menunjukan kegagalan yang terjadi adalah kegagalan fatik. Kemudian dari analisis tegangan pada poros diketahui bahwa tegangan kerja berupa tegangan geser maksimum $\left(\boldsymbol{\tau}_{\text {max }}\right)$, yaitu $52,2 \mathrm{MPa}$ lebih besar dari batas fatik komponen $\left(\mathrm{S}_{\mathrm{se}}\right)$, yaitu $27,95 \mathrm{MPa}$ sehingga kegagalan bisa terjadi. 
W. D. Putra dan P. T. Iswanto / Journal of Mechanical Design and Testing 2(2), (2020), 137-146

\section{KESIMPULAN}

1. Model kegagalan yang terjadi pada poros Shipping Pump P-1B adalah kegagalan fatik berdasarkan adanya awal retak, pertumbuhan retak lambat yang ditunjukkan oleh penampakan serat halus dan daerah patah seketika yang ditunjukkan oleh penampakan butiran kasar pada penampang patahan.

2. Kegagalan poros terjadi dengan diawali oleh awal retak di ujung alur pasak yang mendapat desakan dari pasak dan dengan bertambahnya jumlah putaran poros, retakan cenderung semakin ke dalam dan secara bertahap mengurangi luas penampang hingga akhirnya melemahkan material sampai terjadi patahan sempurna.

3. Poros Shipping Pump P-1B dapat mengalami kegagalan fatik karena tegangan kerja yang didominasi tegangan geser, nilainya lebih besar dari tegangan batas fatik komponen. Faktor terbesar yang mengurangi nilai tegangan batas fatik adalah faktor konsenstrasi tegangan dimana radius alur pasak terlalu kecil.

4. Rekomendasi agar tidak terjadi kegagalan serupa adalah memperbesar radius pada alur pasak untuk memperkecil konsentrasi tegangan, meningkatkan penyelesaian akhir permukaan dan mengganti bahan poros dengan bahan yang memiliki tegangan tarik maksimum lebih tinggi karena nilai tegangan batas fatik berhubungan erat dengan tegangan tarik maksimum.

\section{DAFTAR PUSTAKA}

Girdhar, Paresh dan Moniz, Octo, 2005, Practical Centrifugal Pumps Design, Operation and Maintenance, Elsevier, Burlington.

Bloch, H. P. dan Geitner, F. K., 1999, Machinery Failure Analysis and Troubleshooting, Gulf Professional Publishing, Houston.

Haryadi, G. D., Pertiwanda, Suluh, Ismail, Rifky, 2017, Failure Analysis on Shaft of Circulating Water Pump at Power Plant, Prosiding SNTTM XVI, Surabaya, 5-6 Oktober 2017.

Supriyono dan Adjiantoro, Bintang, 2010, Analisa Kegagalan Poros Pompa Air Laut Pada Unit PLTU, Jurnal Ilmiah Teknologi dan Rekayasa Vol. 15, Depok, 15 Desember 2010.

Gere, J.M., 2004, Mechanics of Materials, Sixth Edition, Thomson Learning, Inc., Belmont.

Bhandari, V. B., 2010, Design of Machine Elements, Third Edition, McGraw-Hill, USA.

Askeland, D. R., Fulay, P. P., Wright, W. J., 2010, The Science and Engineering of Materials, Sixth Edition, Cengage Learning, Stamford.

ASM, 2004, ASM Handbook Vol. 9: Metallography and Microstructure, ASM International.

Peckner, Donald dan Bernstein, I. M., 1977, Handbook of Stainless Steel, McGraw-Hill, New York.Environ Saf 2016; 134:455-61. https://doi.org/10.1016/j. ecoenv.2016.01.023. 